\title{
Influence of Multi-pass Friction Stir Processing on Microstructure and Mechanical Properties of Die Cast Al-7Si-3Cu Aluminum Alloy
}

\author{
L. John Baruch ${ }^{1}$ R. Raju' ${ }^{2}$ V. Balasubramanian ${ }^{3}$ A. G. Rao ${ }^{4}$ I. Dinaharan ${ }^{5}$
}

Received: 26 September 2015/Revised: 1 February 2016/Published online: 1 April 2016

(C) The Chinese Society for Metals and Springer-Verlag Berlin Heidelberg 2016

\begin{abstract}
The influence of overlap multi-pass friction stir processing on the microstructure and the mechanical properties, in particular, strength, ductility and hardness of die cast $\mathrm{Al}-7 \mathrm{Si}-3 \mathrm{Cu}$ aluminum alloy was investigated. It was observed that increase in the number of overlap passes friction stir processing resulted in significant refinement and redistribution of aluminum silicon eutectic phase and elimination of casting porosities. The microstructural refinement by the friction stir processing not only increases the ultimate tensile strength from 121 to $273 \mathrm{MPa}$, but also increases the ductility as observed by the increase in fracture strain from $1.8 \%$ to $10 \%$. Analysis of the fractured surface reveals that the microstructural refinement obtained by friction stir processing plays a vital role in transforming the fracture mode from completely mixed mode to the ductile mode of the fracture with increasing number of passes. The change in the size, shape, morphology and distribution of eutectic silicon particles and elimination of the porosities are the main reasons for the increases in tensile strength and ductility due to friction stir processing.
\end{abstract}

KEY WORDS: Friction stir processing; Overlap multi-pass; Microstructure; Mechanical properties

Available online at http://link.springer.com/journal/40195

I. Dinaharan

dinaweld2009@gmail.com

1 Department of Mechanical Engineering, Madanapalle Institute of Technology and Science, Madanapalle, Andhra Pradesh 517325, India

2 Department of Industrial Engineering, College of Engineering, Anna University, Chennai, Tamil Nadu 600025, India

3 Department of Manufacturing Engineering, Centre for Materials Joining and Research (CEMAJOR), Annamalai University, Annamalai Nagar, Chidambaram, Tamil Nadu 608002, India

4 Marine Materials Division, Naval Materials Research Laboratory, Thane, Maharashtra 421506, India

5 Department of Mechanical Engineering Science, University of Johannesburg, Auckland Park Kingsway Campus, Johannesburg 2006, South Africa

\section{Introduction}

$\mathrm{Al}-\mathrm{Si}-\mathrm{Cu}$ alloys are widely used to cast high-strength components in aerospace and automobile industries. However, porosity, coarse acicular Si particles and coarse aluminum dendrites in the cast structure reduce the mechanical properties of the castings, particularly the ductility, toughness and fatigue strength [1,2]. Eutectic modification and high-temperature heat treatment are widely used to modify the cast microstructure [3, 4]. Severe plastic deformation (SPD) processes such as equalchannel angular pressing or extrusion (ECAP or ECAE) can be employed for improving the mechanical properties of alloys by refining the microstructure. The microstructure and mechanical properties of the as-cast and ECAPed AZ61 alloys were compared by Jiang et al. [5]. They reported that the microstructure of the as-cast AZ61 alloys can be refined very well by ECAP. The mechanical properties of the ECAPed AZ61 alloys were significantly 
improved due to the refined microstructure. According to Jiang et al. [6], the mechanical properties of as-cast $\mathrm{Mg}-$ 9Al-Zn alloy at room temperature such as yield strength, ultimate tensile strength and elongation can be enhanced heavily by ECAE. In that work they found, it is the fine and homogenous microstructure that leads to enhancement of room temperature mechanical properties of the processed billets.

Friction stir processing (FSP), an expansion based on the principle of friction stir welding (FSW) [7], is reported to be an effective route to refine the microstructure, eliminating the casting porosities and thereby enhancing the mechanical properties of cast $\mathrm{Al}-\mathrm{Si}$ alloy [8]. FSP is a solid-state processing technology, in which a rotating tool with pin and shoulder is inserted into a single piece of material and traversed along the desired path to cover the region of interest. A volume of processed material is produced by material movement around the pin. During this process, the material undergoes intense thermo-mechanical deformation, resulting in the generation of fine recrystallized grains with fragmentation and redistribution of the second-phase particles in the processed region or stir zone.

Process parameters are the key art of friction stir processing. Specifying the tool geometry and the stirring conditions (rotational and translational speeds) are important issues in FSP in order to obtain the desired grain refinement. The rotation of the tool results in stirring and mixing of material around the rotating pin and the translation of tool moves the stirred material from the front to the back of the pin and finishes the welding process. The input process/welding parameters influence the heat generation and the flow of the plasticized material, and eventually they affect the microstructure and the mechanical properties of the processed volume/weldment. The resulting microstructure is composed of three primary zones: the heat-affected zone (HAZ), the thermo-mechanically affected zone (TMAZ) and the stir zone (SZ).

In cast A356 aluminum alloy, FSP resulted in a significant breakup of coarse acicular Si particles and the primary aluminum dendrites. This process produces a homogeneous distribution of $\mathrm{Si}$ particles in the aluminum matrix and nearly eliminating all casting porosity $[9,10]$. FSP can be used as a tool to locally modify the microstructures in the regions experiencing high fatigue loading and thus significantly improve the overall performance of aluminum castings, as evidenced by Sharma et al. [11]. Also, Ma et al. [9] reported formation of supersaturated solid solution of A356 after FSP with enhanced mechanical properties after post-FSP aging treatment.

Santella et al. [12] studied the effect of friction stir processing on the mechanical properties of the cast aluminum alloys A319 and A356. They reported that the ultimate tensile strengths, ductilities and fatigue lives of both alloys were increased by the friction stir processing. Nascimento et al. [13] have achieved a significant increase in the formability of friction stir processed AA5083 and AA7022 alloys. Friction stir processing of hypereutectic Al-30Si alloy was studied by Rao et al. [14]. They reported that two-pass FSP with $100 \%$ overlapping on the top of the first pass itself has a pronounced effect on the size, the shape and the distribution of $\mathrm{Si}$ particles. The tensile strengths of the multi-pass friction stir processed (MP-FSP) specimens are much higher than that of ADC 12 die cast aluminum alloy, as evidenced by Nakata et al. [15].

Rayes et al. [16] analyzed the influence of multi-pass friction stir processing on the microstructural and mechanical properties of aluminum alloy 6082 . They found from tensile test results that there is a good agreement between UTS and the hardness value as well as the particle size, where the UTS increases with increasing hardness and reducing the particle size. Cui et al. [17] investigated the effect of FSP parameters and in situ passes on the microstructure and the tensile properties of $\mathrm{Al}-\mathrm{Si}-\mathrm{Mg}$ casting. They concluded that for the multi-pass FSP, the two-pass FSP sample exhibited an obvious advantage in the microstructure modification and the tensile properties compared with the one-pass sample. Naersh et al. [18] studied a bottom-up approach for optimization of friction stir processing parameters of aluminum 2024-T3 alloy. They found that the proper combination of the strength and the ductility was obtained with FSP, which is not possible by other severe plastic deformation (SPD) techniques.

Applying FSP to the as-cast LM $13 \mathrm{Al}$ alloy, it decreases the brittleness significantly and after each pass of FSP the ductility increases as reported by Tutinchilar et al. [19]. Yadav et al. [20] analyzed the effect of friction stir processing on the microstructure and the mechanical properties of aluminum. They concluded that the strength of the FSPed material improved significantly and at the same time the ductility was retained.

From published literature, it is understood that FSP can be effectively used for modifying the microstructure. Most of the published information is focused on one-pass FSP, but information on multi-pass FSP is very scant. Hence, the present work is aimed to study the effect of multi-pass friction stir processing on the microstructural refinement and resulting mechanical properties of die cast alloy AS7U3G and also to study the effect of post-FSP heat treatment response.

\section{Experimental}

The chemical composition of AS7U3G alloy is presented in Table 1. The alloy used for FSP was cut into rectangular pieces of the dimensions $150 \mathrm{~mm} \times 50 \mathrm{~mm} \times 10 \mathrm{~mm}$. Figure 1 shows the friction stir processing setup and tool. 
Table 1 Chemical composition (wt\%) of cast AS7U3G aluminum alloy

\begin{tabular}{lllllllll}
\hline $\mathrm{Si}$ & $\mathrm{Fe}$ & $\mathrm{Cu}$ & $\mathrm{Mn}$ & $\mathrm{Mg}$ & $\mathrm{Zn}$ & $\mathrm{Cr}$ & $\mathrm{Ti}$ & $\mathrm{Al}$ \\
\hline 7.7 & 0.48 & 3.24 & 0.31 & 0.19 & 0.09 & 0.02 & 0.05 & $\mathrm{Bal}$. \\
\hline
\end{tabular}

FSP tool was fabricated from high carbon steel with concave shoulder. An indigenously designed and developed FSW machine (15 hp; $3000 \mathrm{rpm} ; 25 \mathrm{kN}$ ) was used for FSP. The tool rotation and tool traverse speeds were kept constant at $600 \mathrm{rpm}$ and $12 \mathrm{~mm} / \mathrm{min}$, respectively, in all the experiments. Two-pass and three-pass FSP experiments were performed with $100 \%$ overlap over the previous processed zone.

The specimens for microstructural characterization, the tensile and hardness tests were machined from the stir zone. ASTM E8 M guideline was followed for fabricating the tensile test specimens. The specimens for the tensile tests were machined from the longitudinal direction parallel to the direction of processing. The specimens have a gauge length of $25 \mathrm{~mm}$, gauge thickness of $3 \mathrm{~mm}$, grip length of $15 \mathrm{~mm}$ and grip width of $24 \mathrm{~mm}$. Vickers microhardness tests were carried out using Wilson Wolpert microhardness tester. A load of $0.5 \mathrm{~kg}$ and a dwell period of $10 \mathrm{~s}$ were used. Both the base material and the FSPed zones were examined by scanning electron microscope (SEM) to characterize the microstructural refinement. Image Pro Plus ${ }^{\circledR}$ image analysis software was utilized for quantitative analysis of $\mathrm{Al}-\mathrm{Si}$ eutectic particles. The specimen for the microstructural analysis was initially ground with using various grades of emery papers, and $1-\mu \mathrm{m}$ diamond paste was used for final polishing. The base material and processed zone were etched with $0.5 \%$ hydrofluoric acid.

\section{Results}

\subsection{Microstructure}

Figure 2 illustrates typical SEM micrographs of the as-cast base alloy, one-pass stir zone, two-overlap pass stir zone and three-overlap pass stir zone. These micrographs distinctly reveal the significant effect of friction stir processing on the size, the shape and the distribution of $\mathrm{Al}-\mathrm{Si}$ eutectic particles with increasing number of passes. However, the size of the Al-Si eutectic particles in the stir zones decreases with increasing number of overlap FSP passes. Also, the overlap passes not only refine the Al-Si eutectic particle interconnected network but also homogenize the microstructure. Figure 2a-d clearly indicates the extent of refinement and the area fraction of $\mathrm{Al}-\mathrm{Si}$ eutectic particles of each overlap pass, showing more refined and homogeneous structure in three-overlap FSPed alloy.

Figure 2a1-d1 shows the energy-dispersive spectra of base metal and the stir zones of one-pass, two-pass and three-pass FSPed specimens. The energy-dispersive spectra (EDS) of base metal showed the presence of all the alloying elements, but the amount of magnesium quantified is very less. In the stir zones of one-pass, two-pass and three-pass samples, magnesium was not detected by EDS. Similar results were also showed by the work of Ma et al. [9], revealing dissolution of coarse $\mathrm{Mg}_{2} \mathrm{Si}$ precipitates in the as-cast A356 sample after FSP. The accelerated dissolution of the $\mathrm{Mg}_{2} \mathrm{Si}$ precipitates during a short period of the FSW cycle was attributed to significantly accelerated diffusion rates and shortened diffusion distances of the solutes resulting from intense plastic deformation and material mixing [9]. Because of fast cooling cycle during (a)

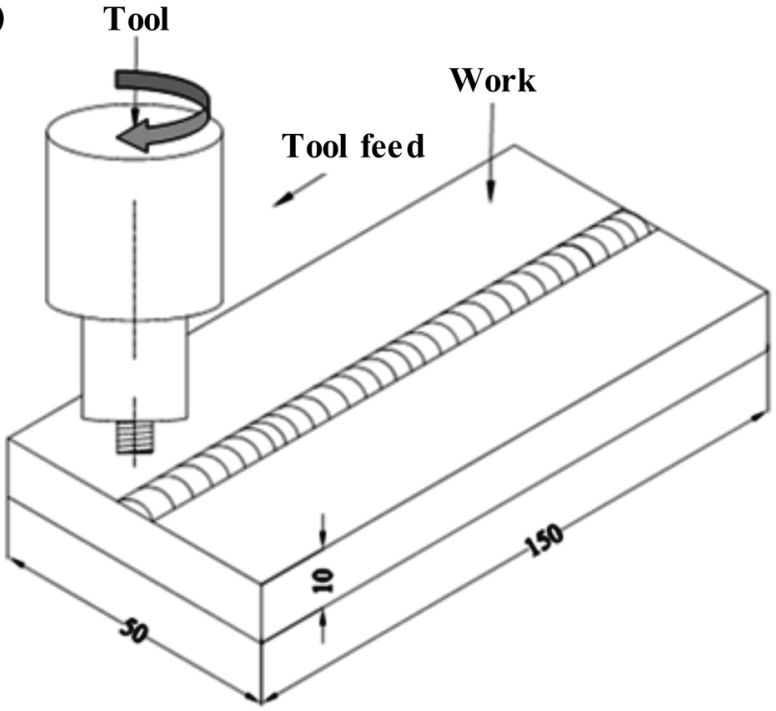

(b)

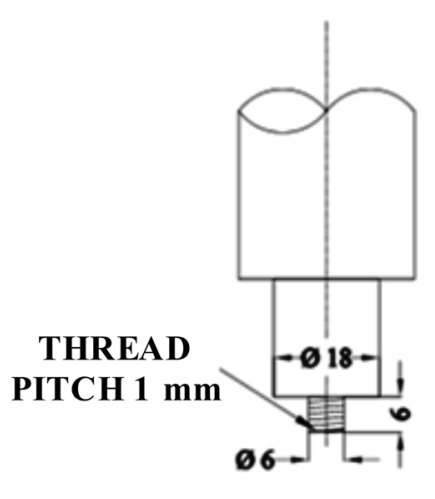

Fig. 1 Friction stir processing setup and tool: a workpiece and tool; b tool dimensions (all dimensions in $\mathrm{mm}$ ) 

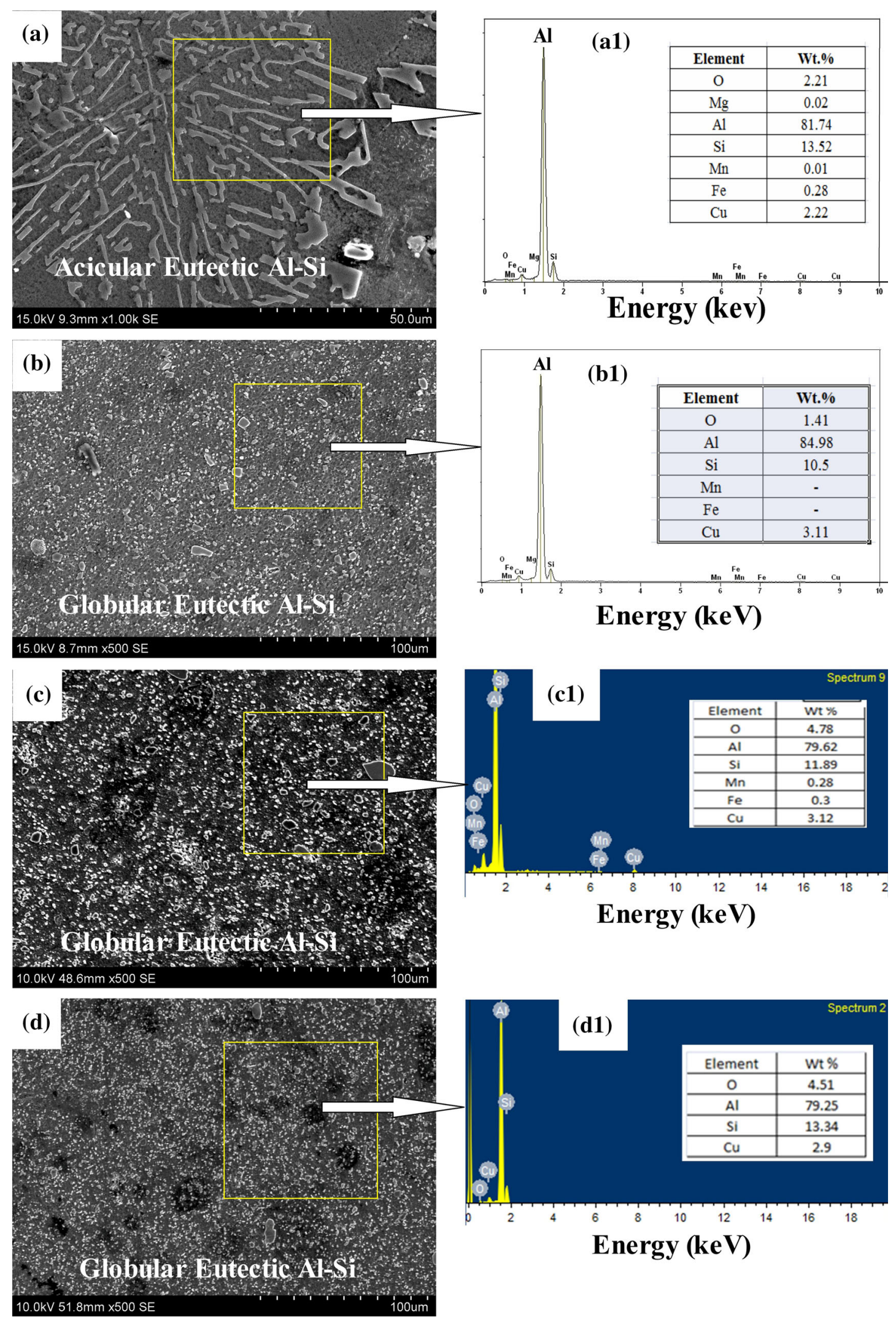

Fig. 2 Cast alloy a, a1, one-pass FSP stir b, b1, two-pass FSP stir $\mathbf{c}, \mathbf{c} 1$ and three-pass FSP stir d, d1 zone SEM micrographs and corresponding energy-dispersive spectra of the FSP stir zones 
FSP, majority of solutes were retained in the matrix, thereby producing supersaturated solid solution in FSP processed alloy. Therefore, after three-pass FSP the alloy was subjected to artificial aging treatment at $100{ }^{\circ} \mathrm{C}$. For the FSPed zone of three-pass sample subjected to heat treatment (HT), it did not change the distribution of $\mathrm{Si}$ particles but resulted in significant particle growth (Fig. 3a). However, after artificial aging it is not possible to reveal the distribution of the precipitates $\left(\mathrm{Mg}_{2} \mathrm{Si}\right.$ and $\mathrm{CuAl}_{2}$ ) by $\mathrm{SEM}$, but the energy-dispersive analysis clearly indicates the presence of these precipitates in Fig. $3 \mathrm{a} 1$.

Table 2 shows the quantitative microstructural characterization result of eutectic Si particle in the cast AS7U3G alloy and after one-, two-, three-overlap friction stir processing and three-overlap FSP after artificial aging. The $\mathrm{Al}-\mathrm{Si}$ eutectic phases are in a form of large interconnected network of acicular-shaped particles in the cast alloy (Fig. 2a). The sizes of the Al-Si eutectic particles in base metal are in the range of $1.12-23.36 \mu \mathrm{m}$, with aspect ratio of 3.70 , and the measurements are more than 100 particles. However, after one pass of FSP, the average Si particle size value was drastically reduced to $(1.17 \pm 1.00) \mu \mathrm{m}$. Further reduction in the average $\mathrm{Al}-\mathrm{Si}$ eutectic particle size values to 0.86 and $0.80 \mu \mathrm{m}$ was obtained in the case of two- and three-overlap pass FSP samples, and the measurements are more than $250 \mathrm{Al}-\mathrm{Si}$ eutectic particles. Also, in post-FSP precipitation hardening, the average Si particle size and the aspect ratio were increased to 1.47 and $1.72 \mu \mathrm{m}$, respectively. This indicates that the precipitation hardening has resulted in substantial particle growth. Although the size reduction in the $\mathrm{Al}-\mathrm{Si}$ eutectic silicon particles from one to three-pass FSP was not significant, the decrease in aspect ratio, defined as the ratio of length $(L)$ to width $(W)$, was noticeable. The aspect ratio $(\Phi)$ is given by Eq. (1).

$\Phi=L / W$.

\subsection{Tensile Properties}

The longitudinal tensile properties, such as yield strength, tensile strength and ductility of the FSPed materials, were evaluated. Data from the tensile behavior of the as-cast and FSPed materials are presented in Fig. 4. The tensile strengths of the one-pass, two-pass and three-pass FSPed materials are significantly higher than that of the as-cast alloy. The tensile strength of three-pass FSPed material is $273 \mathrm{MPa}$ which is 2.25 times higher that of the as-cast alloy (121 MPa). Generally, the increase in the strength leads to decrease in ductility, but the FSP of this alloy resulted in enhancing the ductility from $1.8 \%$ to $10 \%$ due to uniform distribution of fine eutectic precipitates throughout the matrix. Three-pass FSP + heat treatment produced a tensile strength of $312 \mathrm{MPa}$, equivalent to $157 \%$ increase as compared to the as-cast alloy and around $15 \%$ increase as compared to the three-pass FSP sample without HT. Post-FSP heat treatment has significant effect on the elongation of FSPed material. The elongation under the post-FSP heat treated condition is $20 \%$, which shows that the elongation is doubled for the sample under the post-FSP heat treated condition.

\subsection{Hardness}

The effect of number of passes on the distribution of the hardness across FSP region is presented in Fig. 5. Soft spots found in the casting due to porosity and aluminum dendrite cores were eliminated by friction stir processing. The distribution of the hardness values also appears narrower in the stir zone. This is consistent with its more uniform microstructure. The average hardness values in one-pass, two-pass and three-pass FSPed AS7U3G alloy are lower than that of the as-cast alloy. Microhardness values indicate a softening of the processed material at the
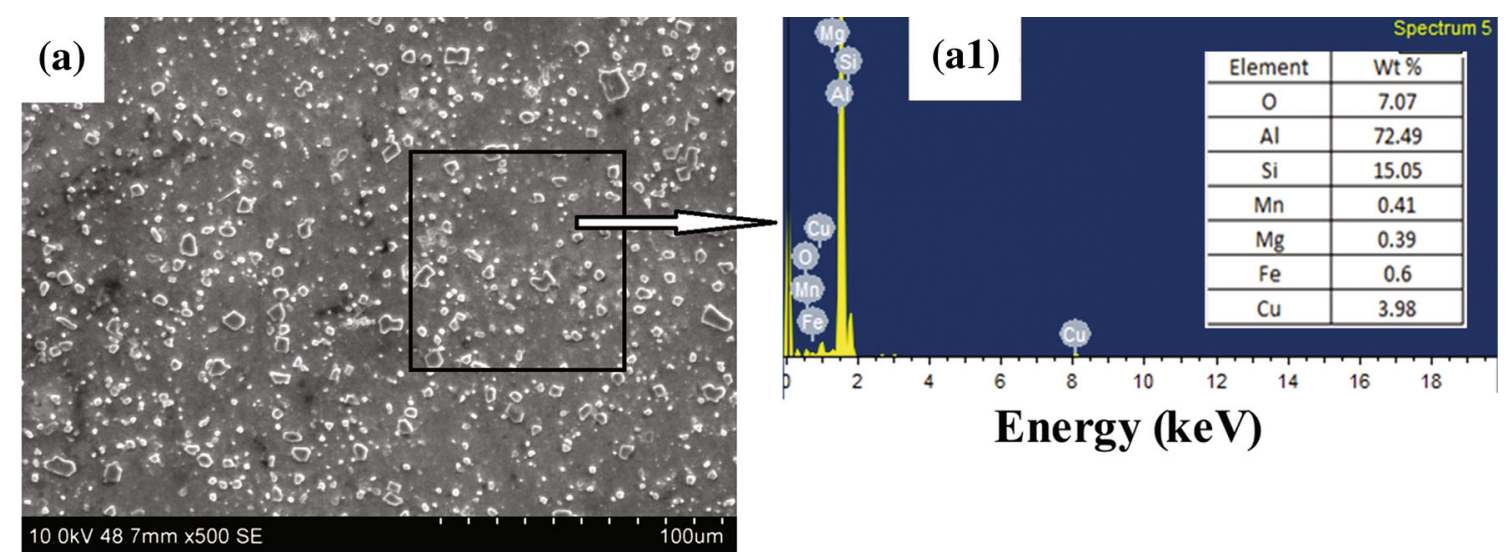

Fig. 3 SEM micrograph a, EDS result a1 of three-pass FSP stir zone with HT 
Table 2 Microstructural characterization (the size and aspect ratio of Si particles) of base metal and FSP zones

\begin{tabular}{|c|c|c|c|c|c|c|}
\hline \multirow[t]{2}{*}{ Condition } & \multicolumn{3}{|c|}{ Silicon particle diameter $(\mu \mathrm{m})$} & \multicolumn{3}{|c|}{ Aspect ratio } \\
\hline & Min & Max & Mean & Min & Max & Mean \\
\hline Base metal & 1.12 & 23.36 & $5.55 \pm 3.73$ & 1.08 & 17.50 & $3.70 \pm 2.45$ \\
\hline One-pass FSP & 0.28 & 11.89 & $1.17 \pm 1.00$ & 1.02 & 11.67 & $1.45 \pm 1.33$ \\
\hline Two-pass FSP & 0.14 & 9.43 & $0.86 \pm 0.78$ & 1.05 & 12.22 & $1.43 \pm 1.14$ \\
\hline Three-pass FSP & 0.09 & 4.23 & $0.80 \pm 0.63$ & 1.02 & 10.12 & $1.35 \pm 1.36$ \\
\hline Three-pass FSP with HT & 0.147 & 12.77 & $1.47 \pm 1.31$ & 1.25 & 12.05 & $1.72 \pm 1.38$ \\
\hline
\end{tabular}

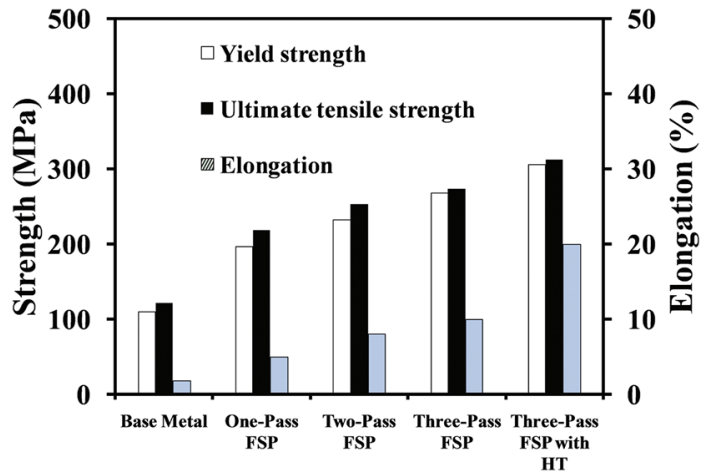

Fig. 4 Tensile test results of base metal and friction stir processed materials

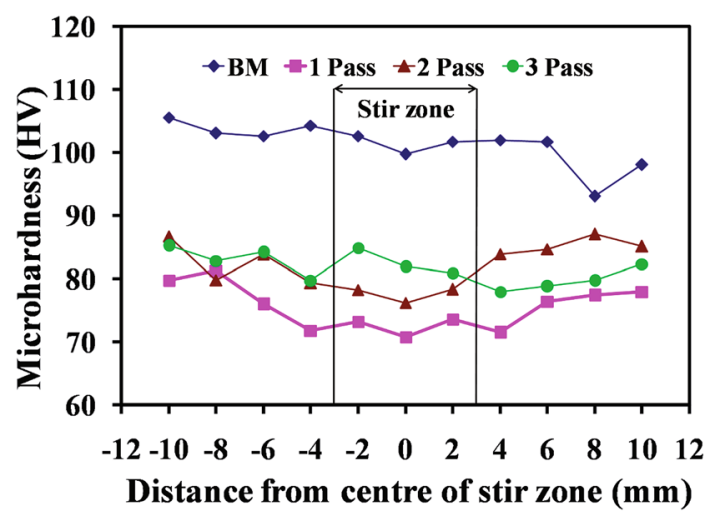

Fig. 5 Microhardness profile across the as-cast and FSPed region of one, two and three pass

friction stir processed zone due to inherent nature of the process. With an increase in number of passes, an increase in the microhardness values was observed in the processed materials. However, post-FSP precipitation hardening treatment had a significant effect on the hardness of the three-pass sample. Nearly $30 \%$ increase was found in average hardness value in three-pass sample after heat treatment. The average hardness value of the three-pass sample after heat treatment was $105 \mathrm{HV}$, which is around $5 \%$ higher compared with the base metal average hardness value $(100 \mathrm{HV})$. The effect of friction stir processing on

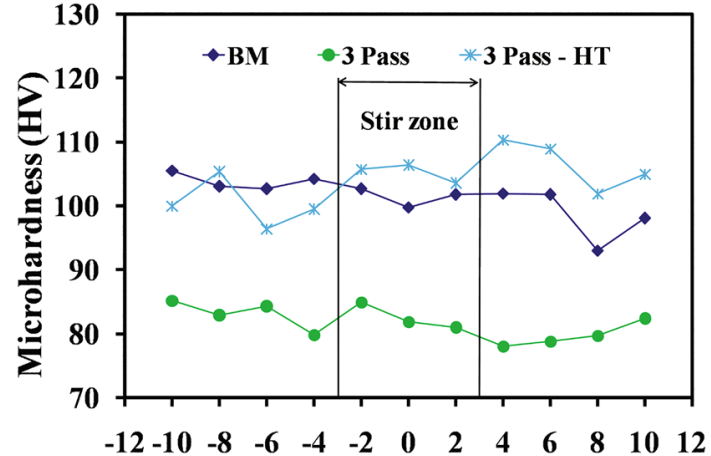

Distance from centre of stir zone $(\mathrm{mm})$

Fig. 6 Microhardness profile across the as-cast, three-pass FSPed region before and after precipitation hardening treatment

the distribution of the hardness across FSP region before and after precipitation hardening is shown in Fig. 6 .

\subsection{Fractography}

The fracture surfaces of the tensile tested specimens of friction stir processed aluminum alloy were analyzed using SEM to reveal the morphologies of fracture surface. Figure 7a-e displays the fractographs of the unprocessed and the processed materials. The fracture surfaces of the FSPed specimens reveal ductile fracture mode; however, the fracture surface of the as-cast alloy exhibits a mixed fracture mode with the cleavage planes and small amount of the dimples. The nucleation and coalescence of the voids around brittle cleavage planes are clearly visible from the fractographs.

\section{Discussion}

\subsection{Effect of Multi-pass FSP on Microstructure}

Multi-pass FSP resulted in significant refinement in the microstructure of the as-cast alloy. The stirring action of the FSP at the nugget zone fragmented the large interconnected eutectic silicon network into fine globular $\mathrm{Al}-\mathrm{Si}$ eutectic particles. The stirring action during FSP causes the 

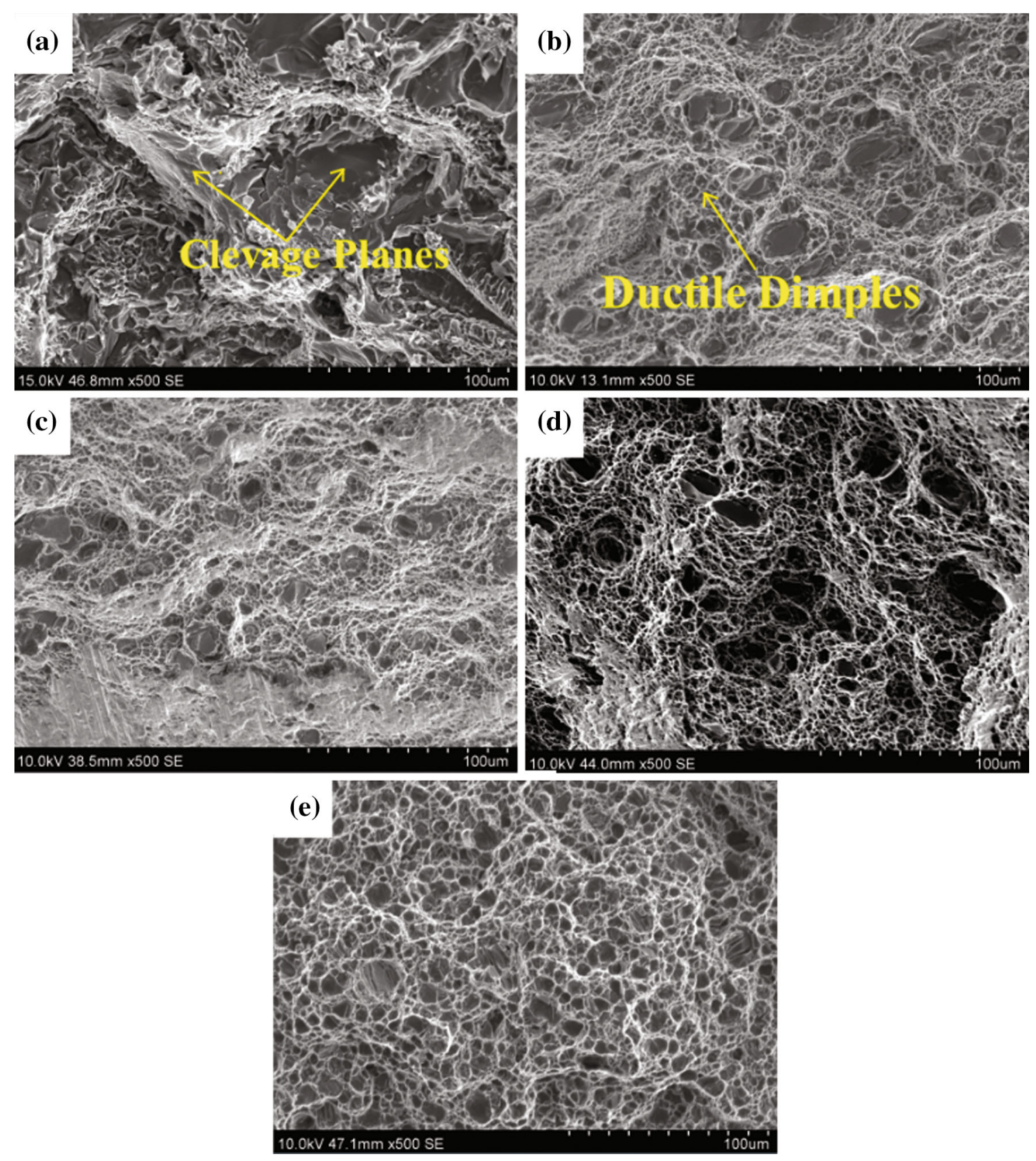

Fig. 7 SEM fractographs of the tensile specimens for the as-cast alloy a, one-pass FSP b, two-pass FSP c, three-pass FSP d, three-pass FSP with HT e

material movement from the advancing to retracting side and therefore is responsible for eliminating the casting porosities. Virtually all traces of dendritic solidified microstructure were eliminated throughout the stir zone. With increasing number of FSP passes, the refinement of $\mathrm{Si}$ particles increased. Two-pass FSP produced a pronounced effect on the microstructure in refining the stir zone and the breakup of the Si particles is further intensified in the threepass FSP. Three-pass FSP produced a remarkable effect on microstructural refinement, homogeneity and densification of $\mathrm{Si}$ particles. The reduction in the average size of $\mathrm{Si}$ particles after one-pass FSP of AS7U3G alloy is 79\%, which further refined to $84.6 \%$ and $85.6 \%$ after two-pass and three-pass FSP, respectively.

In the case of hypoeutectic A356 aluminum alloy, Ma et al. [9] have reported about $86 \%$ reduction in the average size of Si particles after one-pass FSP. They have also reported that the $50 \%$ overlapped multi-pass FSP did not influence the size, aspect ratio and distribution of $\mathrm{Si}$ particles. Rao et al. [14] reported that reduction in the average 
size of the Si particles after one-pass FSP is $98 \%$, which further refined to $99 \%$ after second pass. Ranjit et al. [21] observed that in a two-pass FSP of Al-TiC in situ composite, the grain size was refined substantially after each FSP pass. Silicon particle reduces considerably, as the pass number increases [19]. Similarly, Nakata et al. [15] produced a fine grain structure of $2-3 \mu \mathrm{m}$ in ADC12 die casting alloy via multi-pass FSP. However, for AA2219 Al alloy, one-pass FSP resulted in an average grain size of $6.2 \mu \mathrm{m}$, but in the subsequent passes (two-pass, three-pass) the average grain size showed a marginal increase, reported by Surekha et al. [22]. Nascimento et al. [13] reported that for AA7022-T6 alloy, one-pass FSP reduced the grain size from $160 \mu \mathrm{m}$ to an average grain size of $7.1 \mu \mathrm{m}$ and this remained constant independently of the number of the passes and overlap ratios tested. The result of the present study indicated that with the increase in number of the passes, a decrease in size of $\mathrm{Al}-\mathrm{Si}$ eutectic particles is obtained, which is in agreement with that reported by Tutinchilar et al. [19]. This proves that FSP with 100\% overlap pass continues to homogenize the microstructure in the stir zone. In comparison, the sample processed with three-pass with $100 \%$ overlapping exhibited a more homogeneous processed area with average $\mathrm{Si}$ particle size of $800 \mathrm{~nm}$. During solution treatment at temperature $500{ }^{\circ} \mathrm{C}$, long script-like $\mathrm{Al}-\mathrm{Si}$ eutectic particles in the ascast structure are fragmented and spheroidized. Furthermore, such treatment also leads to significant agglomeration of Si particles. Therefore, a solution heat treatment at $500{ }^{\circ} \mathrm{C}$ for $6 \mathrm{~h}$ resulted in significant spheroidization and agglomeration of long script-like $\mathrm{Al}-\mathrm{Si}$ eutectic particles in the present AS7U3G casting. Ma et al. [23] studied the effect of T6-heat treatment on cast A356Al alloy and reported that fibrous $\mathrm{Si}$ particles in the as-received condition spheroidized completely and coarsened substantially and were distributed along original aluminum dendrite boundaries as a chain. They also reported that, for FSPed samples, the T6-treatment did not change the distribution of Si particles, but resulted in substantial particle growth.

Post-FSP heat treatment resulted in significant coarsening of fine and equiaxed Si particles in the nugget zone of 3P HT sample of AS7U3G. The increase in the average Si particle size in the FSP zone of three-pass FSPed sample after heat treatment is $84 \%$. In the case of A356 aluminum alloy, Ma et al. [23] have reported about $112 \%$ increase in the average Si particle size of one-pass FSPed sample after T6 heat treatment.

\subsection{Effect of Multi-pass FSP on Tensile Properties}

Mechanical properties of the processed materials are important as the objective of FSP is to produce materials with improved properties. From the experimental results
(Fig. 4), it is very clear that multi-pass FSP resulted in remarkable improvement in the longitudinal tensile properties of AS7U3G aluminum alloy arising from the microstructural refinement, homogeneity and densification of AS7U3G casting alloy by multi-pass FSP. From mentioned above, it is seen that these improvements in properties of the mechanical resulted to the following factors: (1) elimination of the casting defects (such as porosity); (2) breaking of eutectic network structure and uniform distribution of the fine Si particles; (3) grain refinement of alpha aluminum matrix. The acicular-shaped $\mathrm{Al}-\mathrm{Si}$ eutectic network provides favorable crack path during deformation. Therefore, the globular $\mathrm{Al}-\mathrm{Si}$ eutectic structure as the barrier may change the path of the dislocation movement, and therefore, FSPed material displayed superior tensile properties than the cast alloy. Cui et al. [17] reported that the two-pass FSP sample exhibited an obvious advantage in the microstructure modification and the tensile properties compared with the one-pass sample.

Usually, cast alloys always show lower ductility as compared to wrought alloys due to the presence of larger grains, porosity and homogeneity of the microstructure. All the processed specimens invariably showed considerable increase in ductility compared with the base metal. The elongation of three-pass FSPed sample is $10 \%$, which is almost 6 times higher than that of the as-cast alloy. By increasing the pass number, both the tensile strength and the elongation are enhanced due to the decrease in $\mathrm{Si}$ particle size with the homogeneous distribution of the particles [19].

Post-FSP heat treatment increased the tensile strength value by around $15 \%$ compared with the three-pass FSPed material without heat treatment. This is due to the re-precipitation of $\mathrm{CuAl}_{2}$ and $\mathrm{Mg}_{2} \mathrm{Si}$ precipitates during the precipitation hardening. The precipitates not only pin the dislocation but also act as a source for nucleation of dislocations, thereby increasing the dislocation density, resulting in the improvements of hardness and also the tensile properties, which are attributed to the homogeneous distribution of the eutectic silicon particles and precipitates in the alloy. Elangovan et al. [24] reported that uniform distribution of finer strengthening $\mathrm{Mg}_{2} \mathrm{Si}$ precipitates, smaller grain size, the lack of a precipitate free zone and higher dislocation density are the reasons for the superior tensile properties of the artificially aged FSW joints. For the AC8A alloy processed by friction stir processing, a post-FSP aging treatment ( $448 \mathrm{~K}$ for $8 \mathrm{~h}$ ) increased the UTS by $15 \%$ but decreased the ductility by $42 \%$ [25].

After FSP, the alloy displays the increases in both strength and ductility. Because the alloy after FSP consists of high density of small $\mathrm{Al}-\mathrm{Si}$ eutectic particles in aluminum matrix, therefore the $\mathrm{Al}-\mathrm{Si}$ eutectic particles, precipitates and high angle grain boundary will act as 
obstacles to dislocation movement. However, strengthening of the alloy from the obstacles will depend on the grain size, Al-Si eutectic particles size and the average distance between the particles. When the average distance between the particles is smaller than the grain size, the particles act as major obstacle to the dislocations movement. With increasing number of FSP passes, the $\alpha$-grain sizes as well as $\mathrm{Al}-\mathrm{Si}$ eutectic particles size were found to decrease simultaneously and the volume fraction of the Al-Si eutectic particles was found to increase. When the small particle pins the mobile dislocations more often than the grain boundaries, the particle size dependence on strength increases obviously, and in this case, the grain boundary acts as only a secondary obstacle to dislocations. This explanation is valid after FSP, and the samples show both higher strength and higher ductility. Post-FSP heat treatment resulted in a significant increase in both yield and ultimate tensile strengths and a remarkable increase in ductility also. Ma et al. [9] reported that two-pass FSP + aging produced a tensile strength of $304 \mathrm{MPa}$ and yield strength of $236 \mathrm{MPa}$ with excellent ductility in the cast A356 sample. This indicates that a combination of optimized FSP parameters and Post-FSP heat treatment can produce maximum strengthening effect in the cast AS7U3G alloy.

\subsection{Effect of Multi-pass FSP on Microhardness}

In general, the hardness of aluminum alloys can be increased by several methods: solid-solution hardening, grain refinement strengthening, work or strain hardening, and precipitation hardening (aging). The effect of frictional heat on the microstructure during one-pass FSP results in generation of dynamic recrystallized grains having low dislocation density causing softening. After one-pass FSP, the average hardness value in the processed material is decreased, compared with the base metal. This decrease could be attributed to the dissolution of the precipitates during FSP. However, the UTS of the processed material is increased. This was already reported in the previous work of Santella et al. [12] and Karthikeyan et al. [26]. Santella et al. [12] investigated the effect of FSP on the hardness and the tensile properties of A319 and A356 aluminum alloys and reported that the thermo-mechanical treatment cycle of the friction stir processing had a hardening effect in A319 and a slight softening effect in A356. They also reported that the decrease in hardness of metal due to FSP did not decrease the UTS but increased by around $30 \%$ when compared to base metal. Karthikeyan et al. [26] studied the effect of FSP on the mechanical properties of cast 2285 aluminum alloy and reported that in all the studied conditions of FSP, the alloy displayed a lower hardness in FSP region, but UTS increased by around 30\% when compared to the base metal. From the above discussion, it is quite clear that the decrease in microhardness of an aluminum alloy after FSP is not an indication of the decrease in ultimate tensile strength. Further, as reported by Santella et al. [12] the tensile properties of A319 and A356 aluminum alloys were strongly dependent on porosity levels, scale of the microstructures. The microhardness and the tensile behavior of friction stir processed AS7U3G aluminum alloy are consistent with this behavior pattern.

With an increase in number of the passes, an increase in the microhardness values was observed in the processed materials and they are lower than that of base metal hardness. This is most probably due to the decrease in $\mathrm{Si}$ particle size accompanied by better particle distribution. Each FSP pass improves distribution of Si particles and reduces size. It is apparent from tensile test results that there is a good agreement between UTS and the hardness values as well as particle size, where UTS increases with increasing hardness and reducing particle size. Surekha et al. [22] observed that for AA 2219 aluminum alloy the average hardness values in the nugget region increased with the increase in number of the passes (up to 3 passes) and they are lower than that of the base metal hardness. Lu et al. [27] reported that the $\mathrm{Si}$ particle size decreases and the microhardness increases as the FSP pass number increases. The major factor for increasing the strength, elongation and hardness is from the better distribution of $\mathrm{Si}$ particles in the processed material as observed by Tutunchilar et al. [19]. Also, in post-FSP heat treatment the hardness was increased from 80 to $105 \mathrm{HV}$ in three-pass overlap FSP. This is due to the complete dissolution of the $\mathrm{Mg}_{2} \mathrm{Si}$ and $\mathrm{CuAl}_{2}$ precipitates during the solid-solution treatment and the subsequent re-precipitation during the precipitation hardening. These precipitates effectively pin the mobile dislocations and cause the hardening of matrix.

\subsection{Effect of Multi-pass FSP on Fracture Surface Analysis}

Furthermore, the analysis and understanding of the tensile curve will give better insight into the behavior of the alloy. Figures $7 \mathrm{a}-\mathrm{e}$ illustrates the schematic representation of deformation behavior of the as-cast alloy and after FSP during uniaxial tensile test. The as-cast alloy is characterized by low strength and ductility, owing to the presence of acicular network of $\mathrm{Al}-\mathrm{Si}$ eutectic particles and the porosities. The failure of the as-cast alloy exhibits a lowenergy mixed-mode fracture. The alloy showed ductile transcrystalline mixed fracture, where decohesion takes place on both the aluminum matrix and silicon particles. The surface is characterized by both ductile dimples and brittle cleavage and showed some deformation feature 
before fracture as shown in Fig. 7a. Figure 7b-e shows the tensile behavior of one-pass to three-pass and three-pass HT FSPed specimens. The dark phase represents the silicon particles. The mechanism during the deformation is mainly by slip with the nucleation and coalescence of microvoids and the dimples. By increasing the FSP pass number, the dimples become smaller and deeper as observed by Tutinchilar et al. [19] in a multi-pass FSP of LM13 eutectic $\mathrm{Al}-\mathrm{Si}$ as-cast alloy. The increase in the ductility and the strength after precipitation hardening treatment is due to more homogeneous structure and more uniform dimples as shown in Fig. 7e.

\section{Conclusions}

1. FSP resulted in the significant breakup of acicular networked fibrous $\mathrm{Al}-\mathrm{Si}$ eutectic particles and aluminum dendrites leading to the redistribution of fine and equiaxed $\mathrm{Al}-\mathrm{Si}$ eutectic particles in the aluminum matrix. Both the size and aspect ratio of $\mathrm{Al}-\mathrm{Si}$ eutectic particles decreased simultaneously with the increase in number of FSP passes.

2. The hardness in the friction stir processed region increased with the increase in number of passes. However, the hardness after FSP was lower than the as-cast alloy. This may be due to reduction in dislocation density, which has more effect on matrix hardening rather than grain boundary hardening.

3. The tensile strength and the ductility of three-pass friction stir processed material were remarkably higher than those of the as-cast alloy.

4. Post-FSP precipitation hardening increased the strength, the ductility and the hardness. The fracture surface revealed the transition of fracture mode from transcrystalline ductile to completely ductile mode.

Acknowledgments The authors are grateful to the Centre for Materials Joining \& Research (CEMAJOR), Department of manufacturing Engineering, Annamalai University, Annamalai Nagar, Tamil Nadu, India, for extending the facilities of Metal Joining Laboratory to carry out this investigation.

\section{References}

[1] D.L. Zhang, L. Zheng, Metall. Mater. Trans. A 27, 3983 (1996)

[2] Y.B. Yu, P.Y. Song, S.S. Kim, J.H. Lee, Scr. Mater. 41, 767 (1999)

[3] G. Atxang, A. Pelayo, A.M. Irrisarri, Mater. Sci. Technol. 17, 446 (2001)

[4] K.T. Kashyap, S. Murali, K.S. Raman, K.S.S. Murthy, Mater. Sci. Technol. 9, 189 (1993)

[5] J. Jiang, Y. Wang, J. Qu, Mater. Sci. Eng. A 560, 473 (2013)

[6] J. Jiang, Y. Wang, Z. Du, J. Qu, Y. Sun, S. Luo, J. Mater. Process. Technol. 210, 751 (2010)

[7] W.M. Thomas, US Patent Patent Application No. 9125978.8 (1991)

[8] Z.Y. Ma, S.R. Sharma, R.S. Mishra, M.W. Mohaney, Mater. Sci. Forum 2891, 426-432 (2003)

[9] Z.Y. Ma, S.R. Sharma, R.S. Mishra, Metall. Mater. Trans. A 37, 3323 (2006)

[10] Z.Y. Ma, S.R. Sharma, R.S. Mishra, Scr. Mater. 54, 1623 (2006)

[11] S.R. Sharma, Z.Y. Ma, R.S. Mishra, Scr. Mater. 51, 237 (2004)

[12] M.L. Santella, T. Engstrom, D. Storjohann, T.Y. Pan, Scr. Mater. 53, 201 (2005)

[13] F. Nacimento, T. Santos, P. Vilaca, R.M. Miranda, L. Quintino, Mater. Sci. Eng. A 506, 16 (2009)

[14] A.G. Rao, B.R.K. Rao, V.P. Deshmukh, A.K. Shah, B.P. Kashyap, Mater. Lett. 63, 2628 (2009)

[15] K. Nakata, Y.G. Kim, H. Fujii, T. Tsumura, T. Komzaki, Mater. Sci. Eng. A 437, 274 (2006)

[16] M.M.E. Rayes, E.A.E. Danaf, J. Mater. Process. Technol. 212, 1157 (2012)

[17] G.R. Cui, D.R. Ni, Z.Y. Ma, S.X. Li, Metall. Mater. Trans. A 45, $5318(2014)$

[18] N. Nadammal, S.V. Satish, S. Suwas, Mater. Des. 65, 127 (2015)

[19] S. Tutinchilar, G.M.K. Besharati, M. Haghpanahi, P. Asadi, Mater. Sci. Eng. A 534, 557 (2012)

[20] D. Yadav, R. Bauri, Mater. Sci. Eng. A 539, 85 (2012)

[21] R. Bauri, D. Yadav, G. Suhas, Mater. Sci. Eng. A 528, 1326 (2011)

[22] K. Surekha, B.S. Murty, K.P. Rao, Surf. Coat. Technol. 202, 4057 (2008)

[23] Z.Y. Ma, S.R. Sharma, R.S. Mishra, Mater. Sci. Eng. A 433, 272 (2006)

[24] K. Elangovan, V. Balasubramanian, Mater. Charact. 59, 1168 (2008)

[25] F.Y. Tsai, P.W. Kao, Mater. Lett. 80, 40 (2012)

[26] L. Karthikeyan, V.S. Senthilkumar, V. Balasubramanian, S. Natarajan, Mater. Des. 30, 2237 (2009)

[27] D. Lu, S. Wei, M. Zhou, Y. Jiang, R. Zhou, Adv. Mater. Res. 1689, 148-149 (2010) 